\title{
Cellular Therapy for Repair of Cardiac Damage after Acute Myocardial Infarction
}

\author{
Matthew M. Cook, ${ }^{1,2}$ Katarina Kollar,, Gary P. Brooke, ${ }^{1}$ and Kerry Atkinson ${ }^{1,2}$ \\ ${ }^{1}$ Adult Stem Cell Laboratory, Mater Medical Research Institute, South Brisbane, QLD 4101, Australia \\ ${ }^{2}$ School of Medicine, University of Queensland, St Lucia, QLD 4072, Australia \\ Correspondence should be addressed to Kerry Atkinson, kerry.atkinson@mater.org.au
}

Received 11 December 2008; Accepted 3 February 2009

Recommended by Gary S. Stein

Cardiovascular diseases, particularly acute myocardial infarction, are the leading causes of death worldwide. Important advances have been made in the secondary treatment for cardiovascular diseases such as heart transplantation and medical and surgical therapies. Although these therapies alleviate symptoms, and may even improve survival, none can reverse the disease process and directly repair the lasting damage. Thus, the cure of cardiovascular diseases remains a major unmet medical need. Recently, cellular therapy has been proposed as a candidate treatment for this. Many stem and progenitor cell populations have each been suggested as a potential basis for such therapy. This review assesses some of the more notable exogenous adult cell candidates and provides insights into the mechanisms by which they may mediate improvement in cardiac function following acute myocardial infarction. Research into the cellular therapy field is of great importance for the further planning of clinical trials for cardiac cellular myoplasty.

Copyright (C) 2009 Matthew M. Cook et al. This is an open access article distributed under the Creative Commons Attribution License, which permits unrestricted use, distribution, and reproduction in any medium, provided the original work is properly cited.

\section{Introduction}

Cardiovascular disease (CVD) is a broad term referring to all diseases that involve the heart and/or blood vessels. CVD is the leading cause of death worldwide, estimated at causing 17.5 million deaths in 2005. Of these an estimated 7.6 million were due to ischaemic heart disease (IHD) which is a subset of CVD and is characterised by occlusion of a coronary artery causing decreased blood flow and deprivation of oxygen and nutrients to the high energy-requiring cardiomyocytes in the myocardium [1]. This situation is also known as acute myocardial infarction (AMI) or more commonly a heart attack. While this may be an acute or transient condition (i.e., the heart is reperfused after a temporary occlusion), the ischemic damage due to loss of blood flow causes significant cardiomyocyte death and the subsequent irreversible formation of a fibrotic scar [2]. This, in turn, leads to dyskinesis of the ventricular wall, diminished heart function, and chronic heart failure (CHF).

Within the last 10-15 years, pharmaceutical therapies (aspirin, angiotensin converting enzyme-inhibitors, $\beta$ blockers), percutaneous coronary interventions, coronary artery bypass graft surgery, left ventricular assist devices and biventricular pacing have made a significant impact on the cardiovascular disease burden. Heart transplantation is also well established, but the need for long-term immune suppression and the chronic donor organ shortages suggest that it is unlikely to evolve into a viable definitive treatment for the majority of persons with cardiac disease. Although these therapies ameliorate symptoms, and may even improve survival, none can claim to directly reverse the disease process itself.

With recent advances in medicine and associated technologies, a number of novel therapies for the repair of the myocardium following ischaemia have been suggested. The most prominent of these is the use of cells to repair existing cardiac damage with bone marrow being the commonest source due to its readily accessible nature and autologous sourcing. Bone marrow mononuclear cells (BMCs), peripheral blood stem cells (PBSCs), mesenchymal stem cells (MSCs), and endothelial progenitor cells (EPCs) have been investigated in animal and human studies. However, many of these cell populations have been incompletely characterised and are thought to be a mixture of several related 
subpopulations. At present, BMCs are the most common source for cell-based therapy and, due to the 40 years of experience with bone marrow transplants used for treating haematological diseases, they have rapidly been applied to clinical trials in severe cardiac disease. Although the first phase I/II controlled clinical trials using BMCs to improve cardiac function after AMI were recently published (with variable results) $[3,4]$, it is still unclear as to which bone marrow cell population contributed to the repair of cardiac muscle damaged by ischaemia in these trials. This review will clarify the potential of purified adult cell populations to repair the damaged myocardium and outline several possible mechanisms of repair.

\section{Stem/Progenitor Cell Populations}

Stem cells are defined by two key characteristics. Firstly, they must be able to self-renew in that they can go through many cell division cycles whilst remaining in an unchanged and undifferentiated state. Their second property is the capacity to differentiate into multiple specialised cell types [5], and the potency of stem cells is often defined by their potential to differentiate. At one end of the spectrum stem cells are able to differentiate into specialised mature cells from all three germ layers. These are termed pluripotent stem cells with embryonic stem cells (derived from blastocyst of a developing embryo) as the prime example. Alternately, multipotent stem cells are restricted to differentiating into certain closely related lineages often of the same germ layer $[5,6]$. Adult (or somatic) stem cells are derived from postnatal or mature tissues and are primarily multipotent. However, some subsets have shown plasticity across multiple germ layers $[7,8]$. Some adult stem cells have a limited capacity for self-renewal and may thus be better classified as adult progenitor cells. Although progenitor cells are also defined by the properties of self-renewal and multipotency, these are observed to a lesser extent compared to pluripotent stem cells. Hence, progenitor cells are more committed to specific lineage differentiation than stem cells (Figure 1).

2.1. Mesenchymal Stem Cells (MSCs). MSCs were first recognised by Friedenstein et al., who identified a plastic adherent, fibroblast-like population (Figure 2) that could regenerate rudiments of normal bone in vivo [9-11]. MSCs were initially identified within the stroma of the bone marrow and were subsequently found to provide support for haematopoiesis by secreting many colony-stimulating factors and growth factors important in the proliferation, differentiation and survival of haematopoietic cells [12-15]. Although a majority of the literature is concerned with bone marrow derived MSCs, they have also, in more recent times, been isolated from other organs including placenta, adipose, cord-blood, and liver [8, 16-21]. Recently, they have been shown to be ubiquitous since they have been shown to be an integral part of the composition of endothelium (perivascular cells or pericytes) [22, 23].

Although no single marker specific for MSCs has yet been described, they are characteristically negative for typical
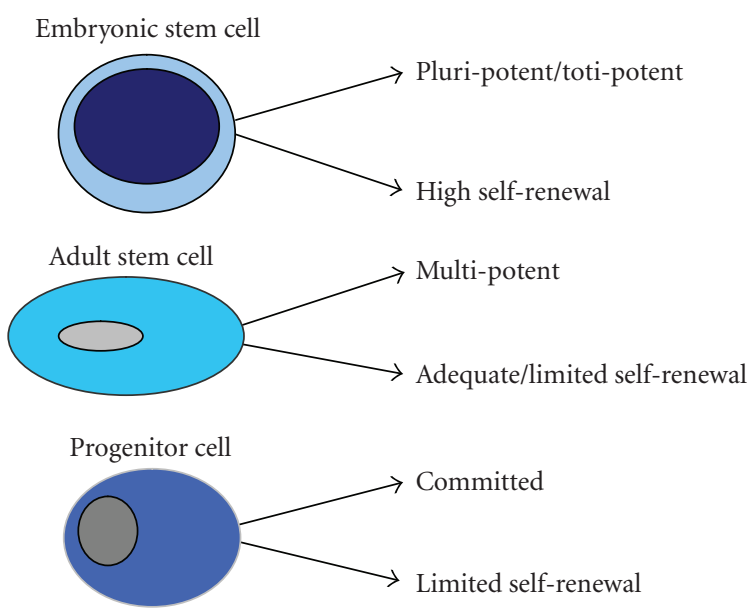

Figure 1: Differentiation and self-renewal potential of embryonic stem cells, adult stem cells, and progenitor cells.

haematopoietic lineage antigens such as CD45, CD34, and CD14 and positive for CD44, CD73, CD90, CD105, CD166, and Stro-1 [24-29]. MSCs also produce a large number of growth factors and cytokines, including vascular endothelial growth factor (VEGF) [13]. This suggests MSCs involvement in paracrine mechanisms. However, the current hallmark for MSCs is their ability to differentiate into mature cell populations of the mesodermal lineage such as bone, cartilage, tendon, muscle, and adipose tissue $[25,28,30,31]$. Interestingly, some groups have also shown MSCs to have plasticity beyond the mesodermal lineage with the ability to differentiate into neurons and astrocytes (ectodermal) as well as hepatocytes (endodermal) $[7,8]$.

MSCs also appear to have a significant advantage for cell therapy in that they are immunologically privileged and even in large outbred animals can be transplanted across major histocompatibility (MHC) barriers without the need for immune suppression [32-34]. This has important implications in that MSCs can be taken from a healthy unrelated donor and cryopreserved ready for use in patients with a wide variety of pathologies [35]. In addition to this relative lack of immunogenicity, MSCs are actively suppressive of $\mathrm{T}$ cell function $[36,37]$. This immune suppressive capability has been successfully exploited in the clinic where unrelated, MHC-unmatched or mismatched MSCs have been used to treat patients with acute graftversus-host disease (GVHD) [33, 38, 39].

MSCs show promise as a cellular therapeutic agent due to their ease of expansion, immuno-privileged status, and ability to self-renew and to differentiate across multiple mature cell lineages. Because of their multipotency, they have been investigated in cardiovascular disease [40, 41], neurological disease [42], osteogenesis imperfecta [43-45], osteoarthritis [46], GVHD [33, 39], and liver fibrosis [47]. Controversially, MSCs have been induced to differentiate into cardiomyocytes in mice [48] and humans [41], and several studies have shown improved myocardial function after myocardial ischaemia in rodents and pigs [40, 41]. This indicates their potential for treatment of damage caused 


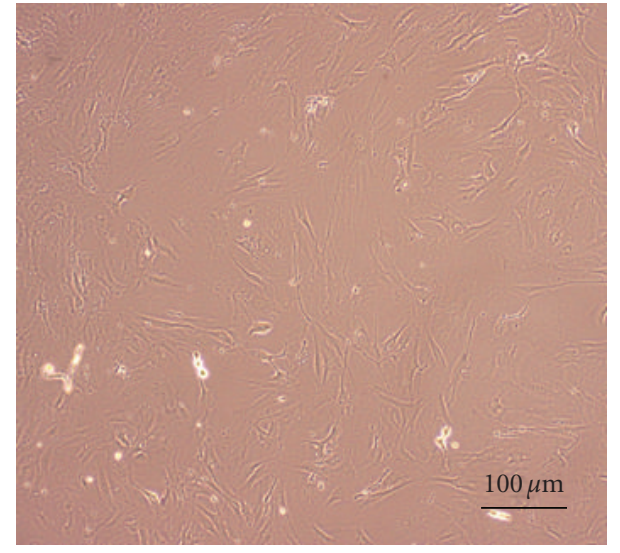

(a)

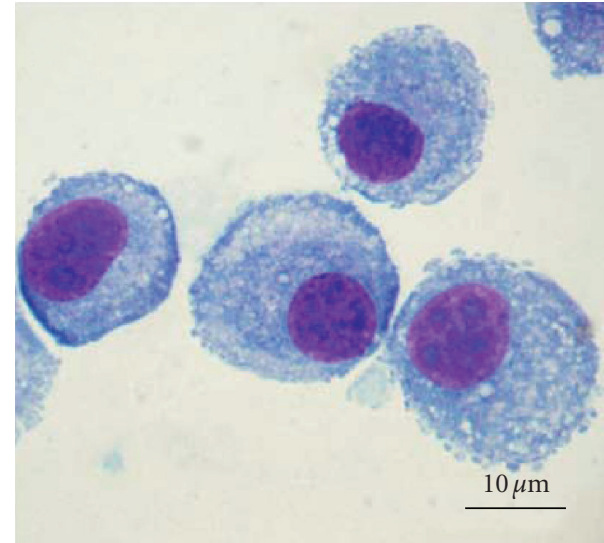

(b)

Figure 2: Mesenchymal stem cell morphology by light microscopy. (a) MSCs culture $(\times 100)$, (b) Cytospin and Giemsa stained $(\times 1000)$.

by ischemic myocardial infarction in human. Finally, there are some reports that MSCs migrate preferentially to sites of inflammation as opposed to the bone marrow, as has been reported in some studies to be the case in unperturbed animals $[26,28]$.

\subsection{Haematopoietic Stem/Progenitor Cells (HSCs/HPCs).} HSCs/HPCs are the best characterised adult stem cell and are the only stem or progenitor cells that are in routine clinical use today. HSCs normally reside in the bone marrow and are responsible for making all blood cell types and thus continually reconstituting the haematopoietic and immune systems $[49,50]$. These cells are used clinically in bone marrow transplants to treat a number of blood disorders including leukaemia, aplastic anaemia, and severe combined immunodeficiency $[51,52]$. The functional hallmark of a true HSCs is the in vivo ability to reconstitute all blood lineages (from a single cell) following otherwise lethal total body irradiation (TBI).

In the human, HSCs/HPCs are identified by cell surface expression of CD34, a cell surface glycoprotein $[49,53,54]$. However, isolation of $\mathrm{CD} 34^{+}$cells from umbilical cord blood, bone marrow, or peripheral blood aphaeresis product leads to a relatively heterogeneous population, while true HSCs, as defined by single-cell repopulation capacity, represent less then $0.1 \%$ of $\mathrm{CD}^{+} 4^{+}$enriched cells [55]. Thus, a CD34 enriched population is often referred to as an HPC population containing lineage-committed cells as well as HSCs. Although CD34 is also expressed in the mouse, the regulation of the $\mathrm{CD} 34$ gene is different to that in the human [53]. Thus, it is not a reliable HPC marker in the mouse. Furthermore, it has been shown that $\mathrm{CD} 34^{- \text {low }}$ murine HSCs can reconstitute the haematopoietic system following TBI [54].

Murine studies of HSCs often use the following markers: ${\mathrm{c}-\mathrm{kit}^{+}, \mathrm{CD} 45^{+} \text {, and lineage }}^{- \text {low }}$. Lineage $\mathrm{e}^{- \text {low }}$ status is commonly defined as negativity for CD5 ( $\mathrm{T}$ cells), CD11b (myeloid cells), CD45R (B cells), Gr-1 (granulocytes), and Ter119 (erythrocytes). This population can be further purified with the addition of the Sca- $1^{+}$marker to the panel and these HSCs are termed LSK cells (Lineage/Sca-1/c-kit) (Figure 3). However, these cells still represent a heterogeneous population with approximately one in ten having the ability to repopulate the haematopoietic system [56]. More recently, the signal lymphocyte activating molecule (SLAM) receptors (CD48, CD150, and CD244) have been used to further enrich the LSK population to derive a more primitive HSC population [57-59]. In humans, earlier HSCs are identified by the phenotypes $\mathrm{CD} 34^{+} \mathrm{CD} 90^{+}$or $\mathrm{CD} 34^{+}$ CD38- [60].

HPCs migrate preferentially to the bone marrow in healthy animals and the molecular mechanisms of this migration are well described, including rolling and tethering of HPCs on bone marrow endothelium, followed by their arrest and firm adhesion to the endothelium [61-63]. It is not known if intravenously injected HPCs migrate preferentially to acutely inflamed tissue.

It is debated as to whether bone marrow cells enriched for HPCs participate in the repair of cardiomyocytes following infarction. Orlic et al. (2001) and Rota et al. (2007) have shown that bone marrow cells enriched for c-kit are capable of differentiating into cardiomyocytes [64, 65]. However, these $\mathrm{c}$-kit ${ }^{+}$enriched populations were heterogeneous and may have contained stromal cell populations. Furthermore, HPCs have been observed to differentiate into skeletal muscle fibres during muscle regeneration [66]. Conversely, it has also been shown that HPCs do not differentiate into cardiomyocytes following infarction and rather take on a mature haematopoietic fate which may, in turn, give rise to differentiated haematopoietic cells, responsible for the inflammatory wound healing process $[67,68]$. Various other actions of HPCs on injured tissue have been proposed including secretion of cytokines and chemokines, inhibition of apoptosis, and suppression of immune reactions $[69,70]$.

2.3. Endothelial Progenitor Cells (EPCs). Historically, neoangiogenesis (the formation of new blood vessels) was thought to occur by the proliferation of existing endothelial cells. However, in 1997 Asahara et al. discovered "putative progenitor endothelial cells" in adult peripheral blood [71]. In 


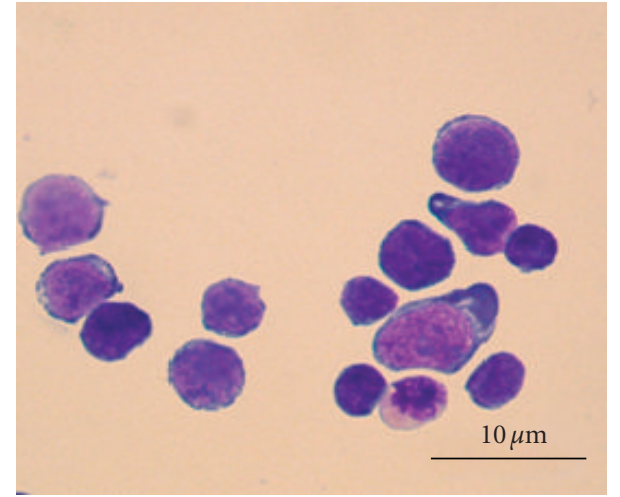

(a)

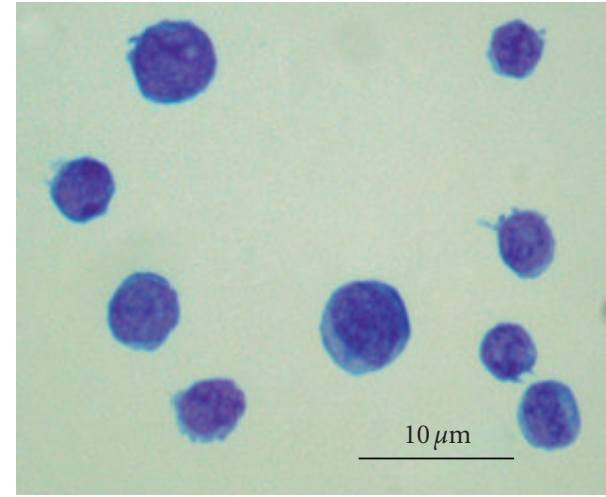

(b)

FIGURE 3: Morphology of (a) haematopoietic progenitor cells displaying a heterogeneous morphology and (b) the more purified LSK showing a more homogeneous morphology (light microscopy $\times 1000)$.

the last 10 years, this discovery has been confirmed and it is now commonly accepted that EPCs play an essential role in adult blood vessel formation, endothelial repair, and endothelial homeostasis $[72,73]$. These postnatal cells have been extensively explored for their innate capacity to contribute to angiogenesis in both pathological and unperturbed states. Like MSCs and HPCs, EPCs can also be derived from the bone marrow. They circulate in peripheral blood in a very low numbers, but can be mobilised into the blood using molecules such as granulocyte colonystimulating factor (G-CSF) [74].

EPCs derived from adult human peripheral blood were initially characterised by expression of both $\mathrm{CD} 34^{+}$and Flk-1 ${ }^{+}$[71]. Flk-1 is also known as vascular endothelial growth factor receptor (VEGFR)-2 in mice and kinase insert domain receptor (KDR) in humans. Along with vascular endothelial growth factor receptor-1 (VEGFR-1, also known as Flt-1), VEGFR-2 serves to mediate the actions of VEGF, which is recognised as an essential regulator of angiogenesis $[74,75]$. VEGFR-2 expression is considered to be a marker of progenitor cell commitment to the endothelial lineage and is now typically used in conjunction with other antigens, such as vascular-endothelium (VE)-cadherin (CD144) and CD31 (also known as platelet/endothelial cell adhesion molecule-1 or PECAM-1) to identify putative angioblasts or EPCs $[76,77]$. Another key marker is CD133 (prominin1) and, like CD34, it is present on both HPCs and cells that exhibit a potent blood-vessel forming capacity [78, 79]. In the developing embryo, EPCs and HSCs arise from a common precursor called the haemangioblast $[80,81]$. Hence, a majority of markers used to identify EPCs are also prevalent on haematopoietic progenitors. Although these markers prove useful in identifying populations enriched for the angioblast or EPCs, it should be recognised that defining hierarchical relationships is far from currently agreed upon $[77,82]$.

It is now more common for EPCs to be isolated from peripheral blood, bone marrow, or umbilical cord blood (UCB) based on their morphologic and adherent characteristics when cultured on fibronectin or collagen-coated plates in the presence of appropriate growth media and supplemental angiogenic differentiation factors. These factors include VEGF, fibroblast growth factor-2 (FGF-2), insulinlike growth factor-1 (IGF-1), and epidermal growth factor (EGF) $[75,76,83,84]$. The majority of cells that appear in early stages of culture (within the first 15 days) are thought to have originated from a CD14 ${ }^{+}$(macrophage/monocyte) subpopulation of mononuclear cells. These cells are often referred to as early-outgrowth endothelial progenitor cells (EO-EPCs) [75, 83, 85]. Conversely, late-outgrowth EPCs (LO-EPCs) do not appear in culture for 2-3 weeks and exhibit the "classic endothelial" phenotype with contact inhibition and cobblestone monolayer morphology and the ability to form in vitro tube-like structures when seeded on Matrigel (Figure 4). These LO-EPCs also show exponential growth kinetics and a capacity for ex vivo expansion $[75,77$, $83,85,86]$.

It has been extensively shown that EPCs are associated with neoangiogenesis following tissue injury in animal models of hind-limb ischaemia and myocardial infarction $[4,84,87,88]$. Conversely, however, administration of EPCs into human patients with CVD is yet to show efficacy with regard to vessel formation, even though these patients had a better clinical outcome [89]. This observation suggests that improvement may have been due to, at least in part, a paracrine function.

2.4. Non-Stem/Progenitor Cell Populations. It is well established that monocytes/macrophages play an important role in angiogenesis, first shown in 1977 [90]. This occurs by the release of tumour necrosis factor- $\alpha$ (TNF- $\alpha$ ), thrombospondin, and angiogenic factors such as VEGF, angiopoietin, and matrix metalloproteinases (MMPs) [91-93]. Cells of the macrophage lineage play a major role in the innate immune response and contribute to wound healing, tissue repair, and bone remodeling [94]. Any disturbance of tissue normality such as infection, aberrant cell turnover, or tissue damage leads to an inflammatory response and a rapid recruitment of macrophages. During inflammation monocytes and macrophages phagocytose foreign particles 


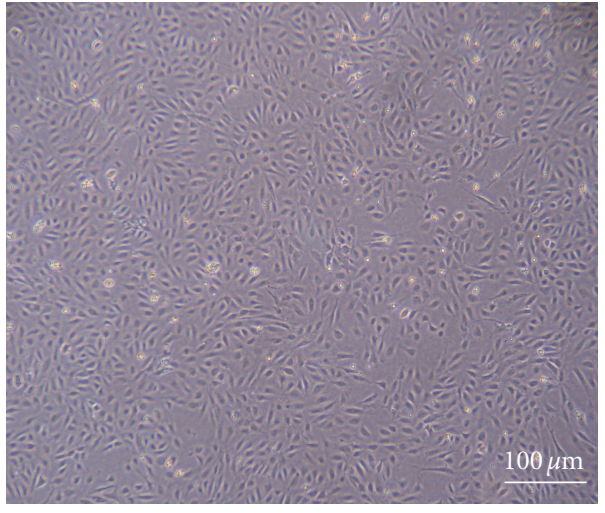

(a)

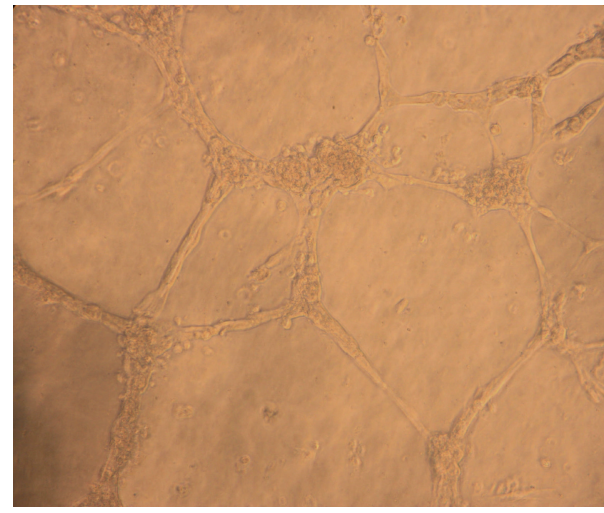

(b)

FIGURE 4: Endothelial progenitor cells derived from human umbilical cord blood (a) exhibit classic cobble-stone morphology (light microscopy $\times 40$ ) and (b) form tube-like structures when seeded on Matrigel basement membrane matrix (light microscopy $\times 100)$.

(cellular debris or pathogens) and stimulate lymphocytes and other immune cells to respond to the pathogen by release of a variety of cytokines and chemoattractants that can modulate the migration of circulating cells and their adhesion to local endothelial cells [2, 91, 93, 95].

A novel lineage of monocytes has recently been isolated that is thought to play a key role in the revascularisation process. These cells are isolated from mice as $\mathrm{CD}_{11 \mathrm{~b}^{+}}$monocytes (or from human as $\mathrm{CD}_{14}{ }^{+}$and $\mathrm{CD} 16^{-}$) and express the angiogenic marker Tie-2 (tunica internal endothelial cell kinase-2) [96-99]. Tie-2 is a receptor tyrosine kinase expressed principally on vascular endothelium and is also expressed on HPCs and EPCs. Its ligands are the angiopoietin growth factors that promote the growth of new blood vessels and are involved with migration of Tie-2-expressing cells to sites of inflammation [96-98]. Tie-2 has also been hypothesised to be involved in the attenuation of proinflammatory mediators.

Tie-2 expressing monocytes (TEMs) have been isolated from the bone marrow of mice by plastic adherence and stimulation with macrophage colony-stimulating factor (MCSF or CSF-1). These cells have a large nucleus surrounded by a cytoplasm with an abundance of vacuoles (Figure 5). They have also been identified in the peripheral blood of mice [96] and from human PBMCs [98, 99]. However, the literature on this subject has been focused on how TEMs may contribute to tumour-associated angiogenesis and thus these cells have often been identified and isolated from various mouse and human tumours. It is thought that TEMs may contribute to tumour angiogenesis by providing paracrine support to nascent blood vessels and by the sequestering of endothelial cells. TEMs produce proangiogenic factors and, when injected in Matrigel matrix plugs implanted under the skin of rodents, promote robust angiogenesis whilst not forming new blood vessels themselves. These data suggest that their recruitment to the site of ischaemic injury is sufficient to support revascularisation $[96,98,100]$.

Monocytes are attracted to the myocardium by overexpression of monocyte chemoattractant protein-1 (MCP-
1), where there is evidence that they form CD31-negative (PECAM) tunnels. Monocytes and macrophages "drill tunnels" using matrix metalloproteinases (MMPs). However it is yet to be demonstrated whether these become new vessels [100-102]. It has been proposed that neoangiogenesis occurs via the contribution of monocytes, macrophages, and circulating EPCs.

\section{Possible Mechanisms of Tissue Repair by Cells}

3.1. Differentiation into Cardiomyocytes and Cell Fusion. Stem cells may have the potential to replace necrotic myocardium, form new cardiomyocytes, and restore cardiac function after AMI [5, 103]. Cardiomyocyte differentiation in vitro has been shown with embryonic stem cells [104], HPCs [64, 65], MSCs [41], and EPCs [105]. Few studies, however, have been able to replicate this phenomenon in vivo and significant cell numbers have failed to differentiate in the myocardium $[67,106]$. Although these studies showed a lack of physical repair of the myocardium, there was still, in most cases, an improvement in cardiac function. These data suggest that there may be other mechanisms mediating functional improvement. One alternative to differentiation is the occurrence of cell fusion to support cardiomyogenesis. However, the occurrence of this is also rare [107-109].

3.2. Paracrine Function. Stem cells secrete many soluble factors that may directly or indirectly have reparative qualities. In cardiac ischaemia, these factors may signal through pathways that act to promote angiogenesis, decrease apoptosis, increase the efficiency of cardiomyocyte metabolism, or modulate inotrophy (formation of fibrous scar) [2]. There is evidence of bone marrow mononuclear cell-conditioned media showing reparative features in preclinical models of AMI [110-113]. This conditioned media contained a variety of cytokines including VEGF, interleukin-1 (IL-1), placental-derived growth factor (PDGF), IGF-1 and MCP-1. It has also been shown that these factors were significantly 


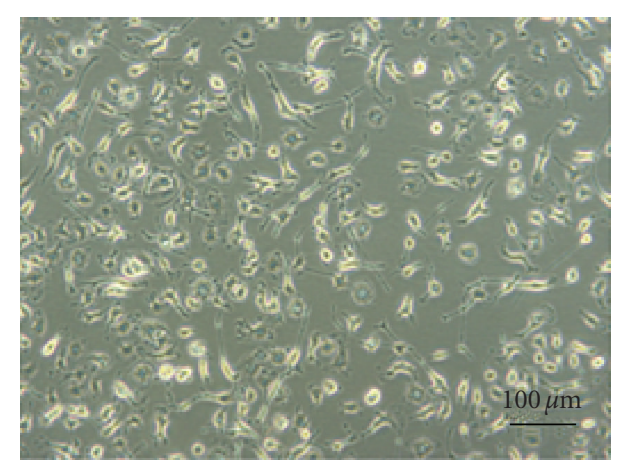

(a)

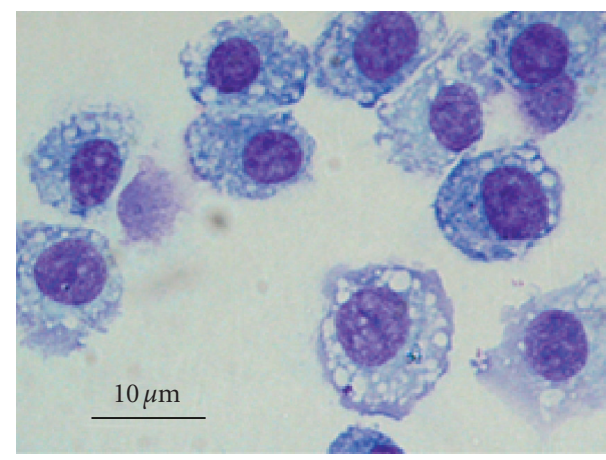

(b)

Figure 5: Analysis of Tie-2 expressing monocytes by (a) culture morphology (light microscopy $\times 100)$ and (b) Giemsa staining (light microscopy $\times 1000)$.

upregulated when the cells are cultured in a hypoxic state [114]. Transfusion of this media led to increased capillary density, decreased infarct size, and improvement of cardiac function following myocardial infarction $[110,112]$. Whilst transfusion of the conditioned media is potentially seen as a useful therapeutic agent, the need for the donor cells to be transfused was still apparent as it was shown that some functional reparative mechanisms only occurred when the bone marrow derived cells were present. There is also a need for such a pool of cytokines to be constantly replenished, a function that can be performed by constant transfusion of conditioned media or a single transfusion of a cellular "cytokine factory".

3.3. Vascular Remodeling. Interventions that increase the perfusion to areas of restricted blood flow may cause salvage of border-zone cardiomyocytes as well as partial reversal of pathological myocardial remodeling. Increased vascularisation may occur via two pathways. Firstly, it may occur by angiogenesis which is the formation of new branches of blood vessels from pre-existing vessels and thus an increase in perfusion. Secondly, it may occur by an increase in diameter of existing vessels causing an increase in local perfusion [104]. The success of both these events is determined by the pre-existence of a vascular network, activation of the endothelium by fluid pressure stress, invasion of bone marrow derived cells, and proliferation of endothelial and smooth muscle cells [115]. Cell therapy may act in a paracrine mechanism to increase the production of proangiogenic cytokines (as mentioned above) and stimulate host cells to remodel the existing vasculature by either forming new branches or converting an arteriole into an artery. Alternately, donor cells may physically embed in the ischaemic tissue and become new vessel branches.

Various studies have shown revascularisation in animal models of hind-limb ischaemia and myocardial infarction with EPCs [87, 116-118], HPCs [64, 66], BMCs [112, 119], and MSCs [120]. One such study by Kocher et al. [81] showed that human mobilised $\mathrm{CD} 34^{+}$cells homed to the infarcted myocardium where they were incorporated into newly developed coronary circulation. However, similar to the differentiation process above, there is limited evidence showing that the cells themselves are directly or physically participating in this event [121]. This, once again, reinforces the potential value of the paracrine function of infused cells as they are often associated with an increase in capillary density in the infarcted region.

3.4. Cardiac Protection. Donor cell secretion of numerous cytokines is believed to attenuate the apoptotic state. For example, IGF-1 [122], hepatocyte growth factor (HGF) [123], and FGF [124] have all been shown to be cardioprotective molecules by attenuation of cardiomyocyte apoptosis.

Another form of cardiac protection is by modification of the immune response and this has subsequently been acknowledged as a potential therapeutic target [104]. This has been shown with MSCs, which suppress T-cell responses and thus have local immunosuppressive functionalities [32, 39]. However, cardiac protection through these mechanisms must be viewed with caution as many proinflammatory and proapoptotic molecules are also involved in angiogenic responses.

\section{Conclusions}

The field of regenerative medicine is quickly evolving and has been applied to many aspects of medicine including the treatment of CVD. Cellular therapy has been proposed as a candidate treatment for CVD. However, a majority of the clinical studies have used mixed populations of cells. Thus, it is still unclear as to which cell population contributed to the repair of cardiac muscle damaged by ischaemia in these trials. This review has outlined the characteristics of some notable purified cell populations that can be used to elucidate the possible roles and contributions of each cell type. Each cell type has its own advantages and limitations towards application for the treatment of CVD. This review has also described the potential mechanisms by which these cells mediate improvement in cardiac function following myocardial infarction. Possible mechanisms of cardiac cellular myoplasty include the generation of proangiogenic 
proteins, stimulation of new blood vessel formation, decrease in apoptosis of cardiac cells, decrease in pathological cardiac remodeling, differentiation into cardiomyocytes and cell fusion. Taking into consideration the various mechanisms of repair and the characteristics of each cell population, a cocktail of specific cell types may need to be considered for successful CVD cellular therapy.

\section{Acknowledgments}

This work was supported by the Mater Foundation, Australian Stem Cell Center, and ANZ Trustees Philanthropy Partners. The authors indicate no potential conflicts of interest.

\section{References}

[1] "Cardiovascular diseases," World Health Organisation (WHO), Geneva, Switzerland, 2007.

[2] N. G. Frangogiannis, "The mechanistic basis of infarct healing," Antioxidants \& Redox Signaling, vol. 8, no. 11-12, pp. 1907-1939, 2006.

[3] A. Abdel-Latif, R. Bolli, I. M. Tleyjeh, et al., "Adult bone marrow-derived cells for cardiac repair: a systematic review and meta-analysis," Archives of Internal Medicine, vol. 167, no. 10, pp. 989-997, 2007.

[4] S. Dimmeler, J. Burchfield, A. M. Zeiher, et al., "Cellbased therapy of myocardial infarction," Arteriosclerosis, Thrombosis, and Vascular Biology, vol. 28, no. 2, pp. 208-216, 2008.

[5] A. P. Beltrami, L. Barlucchi, D. Torella, et al., "Adult cardiac stem cells are multipotent and support myocardial regeneration," Cell, vol. 114, no. 6, pp. 763-776, 2003.

[6] J. C. Kovacic, D. W. M. Muller, R. Harvey, and R. M. Graham, "Update on the use of stem cells for cardiac disease," Internal Medicine Journal, vol. 35, no. 6, pp. 348-356, 2005.

[7] Y. Jiang, B. N. Jahagirdar, R. L. Reinhardt, et al., "Pluripotency of mesenchymal stem cells derived from adult marrow," Nature, vol. 418, no. 6893, pp. 41-49, 2002.

[8] O. K. Lee, T. K. Kuo, W.-M. Chen, K.-D. Lee, S.-L. Hsieh, and T.-H. Chen, "Isolation of multipotent mesenchymal stem cells from umbilical cord blood," Blood, vol. 103, no. 5, pp. 1669-1675, 2004.

[9] A. J. Friedenstein, R. K. Chailakhyan, and U. V. Gerasimov, "Bone marrow osteogenic stem cells: in vitro cultivation and transplantation in diffusion chambers," Cell and Tissue Kinetics, vol. 20, no. 3, pp. 263-272, 1987.

[10] A. J. Friedenstein, K. V. Petrakova, A. I. Kurolesova, and G. P. Frolova, "Heterotopic of bone marrow. Analysis of precursor cells for osteogenic and hematopoietic tissues," Transplantation, vol. 6, no. 2, pp. 230-247, 1968.

[11] M. Owen and A. J. Friedenstein, "Stromal stem cells: marrowderived osteogenic precursors," in Ccllular and Molecular Biology of Vertebrate Hard Tissues, vol. 136 of Ciba Foundation Symposium, pp. 42-60, 1988.

[12] L. Cheng, P. Qasba, P. Vanguri, and M. A. Thiede, "Human mesenchymal stem cells support megakaryocyte and proplatelet formation from $\mathrm{CD} 34^{+}$hematopoietic progenitor cells," Journal of Cellular Physiology, vol. 184, no. 1, pp. 5869, 2000.

[13] R. J. Deans and A. B. Moseley, "Mesenchymal stem cells: biology and potential clinical uses," Experimental Hematology, vol. 28 , no. 8, pp. 875-884, 2000.
[14] W. A. Noort, A. B. Kruisselbrink, P. S. in't Anker, et al., "Mesenchymal stem cells promote engraftment of human umbilical cord blood-derived $\mathrm{CD}^{+} 4^{+}$cells in NOD/SCID mice," Experimental Hematology, vol. 30, no. 8, pp. 870-878, 2002.

[15] Y. Muguruma, T. Yahata, H. Miyatake, et al., "Reconstitution of the functional human hematopoietic microenvironment derived from human mesenchymal stem cells in the murine bone marrow compartment," Blood, vol. 107, no. 5, pp. 18781887, 2006.

[16] S. Barlow, G. Brooke, K. Chatterjee, et al., "Comparison of human placenta- and bone marrow-derived multipotent mesenchymal stem cells," Stem Cells and Development, vol. 17, no. 6, pp. 1095-1107, 2008.

[17] G. Brooke, T. Rossetti, N. Ilic, et al., "Points to consider in designing MSC-based clinical trials," Transfusion Medicine and Hemotherapy, vol. 35, no. 4, pp. 279-285, 2008.

[18] G. Brooke, T. Rossetti, R. Pelekanos, et al., "Manufacturing of human placenta-derived mesenchymal stem cells for clinical trials," British Journal of Haematology, vol. 144, no. 4, pp. 571-579, 2009.

[19] G. Brooke, H. Tong, J.-P. Levesque, and K. Atkinson, "Molecular trafficking mechanisms of multipotent mesenchymal stem cells derived from human bone marrow and placenta," Stem Cells and Development, vol. 17, no. 5, pp. 929-940, 2008.

[20] C. Campagnoli, I. A. G. Roberts, S. Kumar, P. R. Bennett, I. Bellantuono, and N. M. Fisk, "Identification of mesenchymal stem/progenitor cells in human first-trimester fetal blood, liver, and bone marrow," Blood, vol. 98, no. 8, pp. 2396-2402, 2001.

[21] K. Yoshimura, T. Shigeura, D. Matsumoto, et al., "Characterization of freshly isolated and cultured cells derived from the fatty and fluid portions of liposuction aspirates," Journal of Cellular Physiology, vol. 208, no. 1, pp. 64-76, 2006.

[22] M. Crisan, S. Yap, L. Casteilla, et al., "A perivascular origin for mesenchymal stem cells in multiple human organs," Cell Stem Cell, vol. 3, no. 3, pp. 301-313, 2008.

[23] L. da Silva Meirelles, A. I. Caplan, and N. B. Nardi, "In search of the in vivo identity of mesenchymal stem cells," Stem Cells, vol. 26, no. 9, pp. 2287-2299, 2008.

[24] P. A. Conget and J. J. Minguell, "Phenotypical and functional properties of human bone marrow mesenchymal progenitor cells," Journal of Cellular Physiology, vol. 181, no. 1, pp. 67-73, 1999.

[25] M. Dominici, K. Le Blanc, I. Mueller, et al., "Minimal criteria for defining multipotent mesenchymal stromal cells. The International Society for Cellular Therapy position statement," Cytotherapy, vol. 8, no. 4, pp. 315-317, 2006.

[26] E. Javazon, J. Tebbets, K. Beggs, et al., "Isolation, expansion, and characterization of murine, adult bone marrow derived, mesenchymal stem cells," Blood, vol. 102, pp. 180B-181B, 2003.

[27] A. Peister, J. A. Mellad, B. L. Larson, B. M. Hall, L. F. Gibson, and D. J. Prockop, "Adult stem cells from bone marrow (MSCs) isolated from different strains of inbred mice vary in surface epitopes, rates of proliferation, and differentiation potential," Blood, vol. 103, no. 5, pp. 1662-1668, 2004.

[28] M. F. Pittenger, A. M. Mackay, S. C. Beck, et al., "Multilineage potential of adult human mesenchymal stem cells," Science, vol. 284, no. 5411, pp. 143-147, 1999.

[29] P. Bianco, P. G. Robey, and P. J. Simmons, "Mesenchymal stem cells: revisiting history, concepts, and assays," Cell Stem Cell, vol. 2, no. 4, pp. 313-319, 2008. 
[30] E. M. Horwitz, K. Le Blanc, M. Dominici, et al., "Clarification of the nomenclature for MSC: the International Society for Cellular Therapy position statement," Cytotherapy, vol. 7, no. 5, pp. 393-395, 2005.

[31] D. J. Prockop, "Marrow stromal cells as stem cells for nonhematopoietic tissues," Science, vol. 276, no. 5309, pp. 71-74, 1997.

[32] B. J. Jones, G. Brooke, K. Atkinson, and S. J. McTaggart, "Immunosuppression by placental indoleamine 2,3dioxygenase: a role for mesenchymal stem cells," Placenta, vol. 28, no. 11-12, pp. 1174-1181, 2007.

[33] O. Ringdén, M. Uzunel, I. Rasmusson, et al., "Mesenchymal stem cells for treatment of therapy-resistant graft-versushost disease," Transplantation, vol. 81, no. 10, pp. 1390-1397, 2006.

[34] K. Le Blanc, "Immunomodulatory effects of fetal and adult mesenchymal stem cells," Cytotherapy, vol. 5, no. 6, pp. 485489, 2003.

[35] G. Brooke, M. Cook, C. Blair, et al., "Therapeutic applications of mesenchymal stromal cells," Seminars in Cell and Developmental Biology, vol. 18, no. 6, pp. 846-858, 2007.

[36] S. Beyth, Z. Borovsky, D. Mevorach, et al., "Human mesenchymal stem cells alter antigen-presenting cell maturation and induce T-cell unresponsiveness," Blood, vol. 105, no. 5, pp. 2214-2219, 2005.

[37] I. Rasmusson, O. Ringdén, B. Sundberg, and K. Le Blanc, "Mesenchymal stem cells inhibit the formation of cytotoxic T lymphocytes, but not activated cytotoxic T lymphocytes or natural killer cells," Transplantation, vol. 76, no. 8, pp. 12081213, 2003.

[38] K. Le Blanc, F. Frassoni, L. Ball, et al., "Mesenchymal stem cells for treatment of steroid-resistant, severe, acute graftversus-host disease: a phase II study," The Lancet, vol. 371, no. 9624, pp. 1579-1586, 2008.

[39] K. Le Blanc, I. Rasmusson, B. Sundberg, et al., "Treatment of severe acute graft-versus-host disease with third party haploidentical mesenchymal stem cells," The Lancet, vol. 363, no. 9419, pp. 1439-1441, 2004.

[40] L. C. Amado, A. P. Saliaris, K. H. Schuleri, et al., "Cardiac repair with intramyocardial injection of allogeneic mesenchymal stem cells after myocardial infarction," Proceedings of the National Academy of Sciences of the United States of America, vol. 102, no. 32, pp. 11474-11479, 2005.

[41] C. Toma, M. F. Pittenger, K. S. Cahill, B. J. Byrne, and P. D. Kessler, "Human mesenchymal stem cells differentiate to a cardiomyocyte phenotype in the adult murine heart," Circulation, vol. 105, no. 1, pp. 93-98, 2002.

[42] L.-R. Zhao, W.-M. Duan, M. Reyes, C. D. Keene, C. M. Verfaillie, and W. C. Low, "Human bone marrow stem cells exhibit neural phenotypes and ameliorate neurological deficits after grafting into the ischemic brain of rats," Experimental Neurology, vol. 174, no. 1, pp. 11-20, 2002.

[43] R. F. Pereira, M. D. O’Hara, A. V. Laptev, et al., "Marrow stromal cells as a source of progenitor cells for nonhematopoietic tissues in transgenic mice with a phenotype of osteogenesis imperfecta," Proceedings of the National Academy of Sciences of the United States of America, vol. 95, no. 3, pp. 1142-1147, 1998.

[44] E. M. Horwitz, P. L. Gordon, W. K. K. Koo, et al., "Isolated allogeneic bone marrow-derived mesenchymal cells engraft and stimulate growth in children with osteogenesis imperfecta: implications for cell therapy of bone," Proceedings of the National Academy of Sciences of the United States of America, vol. 99, no. 13, pp. 8932-8937, 2002.
[45] K. Le Blanc, C. Götherström, O. Ringdén, et al., "Fetal mesenchymal stem-cell engraftment in bone after in utero transplantation in a patient with severe osteogenesis imperfecta," Transplantation, vol. 79, no. 11, pp. 1607-1614, 2005.

[46] J. M. Murphy, D. J. Fink, E. B. Hunziker, and F. P. Barry, "Stem cell therapy in a caprine model of osteoarthritis," Arthritis and Rheumatism, vol. 48, no. 12, pp. 3464-3474, 2003.

[47] B. Fang, M. Shi, L. Liao, S. Yang, Y. Liu, and R. C. Zhao, "Systemic infusion of FLK1 ${ }^{+}$mesenchymal stem cells ameliorate carbon tetrachloride-induced liver fibrosis in mice," Transplantation, vol. 78, no. 1, pp. 83-88, 2004.

[48] M. Kudo, Y. Wang, M. A. Wani, M. Xu, A. Ayub, and M. Ashraf, "Implantation of bone marrow stem cells reduces the infarction and fibrosis in ischemic mouse heart," Journal of Molecular and Cellular Cardiology, vol. 35, no. 9, pp. 11131119, 2003.

[49] R. G. Andrews, E. M. Bryant, S. H. Bartelmez, et al., "CD34 marrow cells, devoid of $\mathrm{T}$ and $\mathrm{B}$ lymphocytes, reconstitute stable lymphopoiesis and myelopoiesis in lethally irradiated allogeneic baboons," Blood, vol. 80, no. 7, pp. 1693-1701, 1992.

[50] J. L. McKenzie, O. I. Gan, M. Doedens, J. C. Y. Wang, and J. E. Dick, "Individual stem cells with highly variable proliferation and self-renewal properties comprise the human hematopoietic stem cell compartment," Nature Immunology, vol. 7, no. 11, pp. 1225-1233, 2006.

[51] F. R. Appelbaum, "The current status of hematopoietic cell transplantation," Annual Review of Medicine, vol. 54, pp. 491-512, 2003.

[52] M. Mielcarek and R. Storb, "Non-myeloablative hematopoietic cell transplantation as immunotherapy for hematologic malignancies," Cancer Treatment Reviews, vol. 29, no. 4, pp. 283-290, 2003.

[53] Y. Okuno, H. Iwasaki, C. S. Huettner, et al., "Differential regulation of the human and murine CD34 genes in hematopoietic stem cells," Proceedings of the National Academy of Sciences of the United States of America, vol. 99, no. 9, pp. 6246-6251, 2002.

[54] M. Osawa, K.-I. Hanada, H. Hamada, and H. Nakauchi, "Long-term lymphohematopoietic reconstitution by a single CD34-low/negative hematopoietic stem cell," Science, vol. 273, no. 5272, pp. 242-245, 1996.

[55] A. W. Wognum, A. C. Eaves, and T. E. Thomas, "Identification and isolation of hematopoietic stem cells," Archives of Medical Research, vol. 34, no. 6, pp. 461-475, 2003.

[56] A. J. Wagers, R. C. Allsopp, and I. L. Weissman, "Changes in integrin expression are associated with altered homing properties of $\mathrm{Lin}^{-/ \mathrm{lo}} \mathrm{Thy} 1.1^{\mathrm{lo}} \mathrm{Sca}-1^{+} \mathrm{c}-\mathrm{Kit}^{+}$ hematopoietic stem cells following mobilization by cyclophosphamide/granulocyte colony-stimulating factor," Experimental Hematology, vol. 30, no. 2, pp. 176-185, 2002.

[57] M. J. Kiel, O. H. Yilmaz, T. Iwashita, O. H. Yilmaz, C. Terhorst, and S. J. Morrison, "SLAM family receptors distinguish hematopoietic stem and progenitor cells and reveal endothelial niches for stem cells," Cell, vol. 121, no. 7, pp. 1109-1121, 2005.

[58] I. Kim, S. He, O. H. Yilmaz, M. J. Kiel, and S. J. Morrison, "Enhanced purification of fetal liver hematopoietic stem cells using SLAM family receptors," Blood, vol. 108, no. 2, pp. 737744, 2006.

[59] A. Wilson, G. M. Oser, M. Jaworski, et al., "Dormant and selfrenewing hematopoietic stem cells and their niches," Annals of the New York Academy of Sciences, vol. 1106, pp. 64-75, 2007. 
[60] I. L. Weissman and J. A. Shizuru, "The origins of the identification and isolation of hematopoietic stem cells, and their capability to induce donor-specific transplantation tolerance and treat autoimmune diseases," Blood, vol. 112, no. 9, pp. 3543-3553, 2008.

[61] I. B. Mazo, J.-C. Gutierrez-Ramos, P. S. Frenette, R. O. Hynes, D. D. Wagner, and U. H. von Andrian, "Hematopoietic progenitor cell rolling in bone marrow microvessels: parallel contributions by endothelial selectins and vascular cell adhesion molecule 1," Journal of Experimental Medicine, vol. 188, no. 3, pp. 465-474, 1998.

[62] T. Papayannopoulou, "Bone marrow homing: the players, the playfield, and their evolving roles," Current Opinion in Hematology, vol. 10, no. 3, pp. 214-219, 2003.

[63] I. G. Winkler and J.-P. Lévesque, "Mechanisms of hematopoietic stem cell mobilization: when innate immunity assails the cells that make blood and bone," Experimental Hematology, vol. 34, no. 8, pp. 996-1009, 2006.

[64] D. Orlic, J. Kajstura, S. Chimenti, et al., "Bone marrow cells regenerate infarcted myocardium," Nature, vol. 410, no. 6829, pp. 701-705, 2001.

[65] M. Rota, J. Kajstura, T. Hosoda, et al., "Bone marrow cells adopt the cardiomyogenic fate in vivo," Proceedings of the National Academy of Sciences of the United States of America, vol. 104, no. 45, pp. 17783-17788, 2007.

[66] M. Abedi, B. M. Foster, K. D. Wood, et al., "Haematopoietic stem cells participate in muscle regeneration," British Journal of Haematology, vol. 138, no. 6, pp. 792-801, 2007.

[67] L. B. Balsam, A. J. Wagers, J. L. Christensen, T. Kofidis, I. L. Weissman, and R. C. Robbins, "Haematopoietic stem cells adopt mature haematopoietic fates in ischaemic myocardium," Nature, vol. 428, no. 6983, pp. 668-673, 2004.

[68] C. E. Murry, M. H. Soonpaa, H. Reinecke, et al., "Haematopoietic stem cells do not transdifferentiate into cardiac myocytes in myocardial infarcts," Nature, vol. 428, no. 6983, pp. 664-668, 2004.

[69] D. J. Prockop and S. D. Olson, "Clinical trials with adult stem/progenitor cells for tissue repair: let's not overlook some essential precautions," Blood, vol. 109, no. 8, pp. 3147-3151, 2007.

[70] J. L. Spees, S. D. Olson, M. J. Whitney, and D. J. Prockop, "Mitochondrial transfer between cells can rescue aerobic respiration," Proceedings of the National Academy of Sciences of the United States of America, vol. 103, no. 5, pp. 1283-1288, 2006.

[71] T. Asahara, T. Murohara, A. Sullivan, et al., "Isolation of putative progenitor endothelial cells for angiogenesis," Science, vol. 275, no. 5302, pp. 964-967, 1997.

[72] A. Jiang, M. Zhang, and Z. Liu, "Angioblasts in adult and its role in ocular disorders due to neovascularization," Yan Ke Xue Bao, vol. 21, no. 3, pp. 158-162, 2005.

[73] N. Werner and G. Nickenig, "Influence of cardiovascular risk factors on endothelial progenitor cells: limitations for therapy?" Arteriosclerosis, Thrombosis, and Vascular Biology, vol. 26, no. 2, pp. 257-266, 2006.

[74] G. P. Fadini, S. V. de Kreutzenberg, A. Coracina, et al., "Circulating $\mathrm{CD} 34^{+}$cells, metabolic syndrome, and cardiovascular risk," European Heart Journal, vol. 27, no. 18, pp. 2247-2255, 2006.

[75] J. Hur, C.-H. Yoon, H.-S. Kim, et al., "Characterization of two types of endothelial progenitor cells and their different contributions to neovasculogenesis," Arteriosclerosis, Thrombosis, and Vascular Biology, vol. 24, no. 2, pp. 288-293, 2004.
[76] D. A. Ingram, L. E. Mead, H. Tanaka, et al., "Identification of a novel hierarchy of endothelial progenitor cells using human peripheral and umbilical cord blood," Blood, vol. 104, no. 9, pp. 2752-2760, 2004.

[77] M. C. Yoder, L. E. Mead, D. Prater, et al., "Redefining endothelial progenitor cells via clonal analysis and hematopoietic stem/progenitor cell principals," Blood, vol. 109, no. 5, pp. 1801-1809, 2007.

[78] G. Kania, D. Corbeil, J. Fuchs, et al., "Somatic stem cell marker prominin-1/CD133 is expressed in embryonic stem cell-derived progenitors," Stem Cells, vol. 23, no. 6, pp. 791804, 2005.

[79] S. V. Shmelkov, S. Meeus, N. Moussazadeh, et al., "Cytokine preconditioning promotes codifferentiation of human fetal liver $\mathrm{CD}_{133^{+}}$stem cells into angiomyogenic tissue," Circulation, vol. 111, no. 9, pp. 1175-1183, 2005.

[80] U. M. Gehling, S. Ergün, U. Schumacher, et al., "In vitro differentiation of endothelial cells from AC133-positive progenitor cells," Blood, vol. 95, no. 10, pp. 3106-3112, 2000.

[81] A. A. Kocher, M. D. Schuster, M. J. Szabolcs, et al., "Neovascularization of ischemic myocardium by human bonemarrow-derived angioblasts prevents cardiomyocyte apoptosis, reduces remodeling and improves cardiac function," Nature Medicine, vol. 7, no. 4, pp. 430-436, 2001.

[82] D. A. Ingram, N. M. Caplice, and M. C. Yoder, "Unresolved questions, changing definitions, and novel paradigms for defining endothelial progenitor cells," Blood, vol. 106, no. 5, pp. 1525-1531, 2005.

[83] R. Gulati, D. Jevremovic, T. E. Peterson, et al., "Diverse origin and function of cells with endothelial phenotype obtained from adult human blood," Circulation Research, vol. 93, no. 11, pp. 1023-1025, 2003.

[84] C. Kalka, H. Masuda, T. Takahashi, et al., "Transplantation of ex vivo expanded endothelial progenitor cells for therapeutic neovascularization," Proceedings of the National Academy of Sciences of the United States of America, vol. 97, no. 7, pp. 3422-3427, 2000.

[85] C.-H. Yoon, J. Hur, K.-W. Park, et al., "Synergistic neovascularization by mixed transplantation of early endothelial progenitor cells and late outgrowth endothelial cells: the role of angiogenic cytokines and matrix metalloproteinases," Circulation, vol. 112, no. 11, pp. 1618-1627, 2005.

[86] M. Ishikawa and T. Asahara, "Endothelial progenitor cell culture for vascular regeneration," Stem Cells and Development, vol. 13, no. 4, pp. 344-349, 2004.

[87] A. Kawamoto, H.-C. Gwon, H. Iwaguro, et al., "Therapeutic potential of ex vivo expanded endothelial progenitor cells for myocardial ischemia," Circulation, vol. 103, no. 5, pp. 634637, 2001.

[88] S. Rafii and D. Lyden, "Therapeutic stem and progenitor cell transplantation for organ vascularization and regeneration," Nature Medicine, vol. 9, no. 6, pp. 702-712, 2003.

[89] D. G. Katritsis, P. A. Sotiropoulou, E. Karvouni, et al., "Transcoronary transplantation of autologous mesenchymal stem cells and endothelial progenitors into infarcted human myocardium," Catheterization and Cardiovascular Interventions, vol. 65, no. 3, pp. 321-329, 2005.

[90] P. J. Polverini, R. S. Cotran, M. A. Gimbrone Jr., and E. R. Unanue, "Activated macrophages induce vascular proliferation,” Nature, vol. 269, no. 5631, pp. 804-806, 1977.

[91] Å. Dahlqvist, E. Y. Umemoto, J. J. Brokaw, M. Dupuis, and D. M. McDonald, "Tissue macrophages associated with angiogenesis in chronic airway inflammation in rats," 
American Journal of Respiratory Cell and Molecular Biology, vol. 20, no. 2, pp. 237-247, 1999.

[92] L. A. DiPietro and P. J. Polverini, "Angiogenic macrophages produce the angiogenic inhibitor thrombospondin 1," The American Journal of Pathology, vol. 143, no. 3, pp. 678-684, 1993.

[93] E. Elsheikh, M. Uzunel, Z. He, J. Holgersson, G. Nowak, and S. Sumitran-Holgersson, "Only a specific subset of human peripheral-blood monocytes has endothelial-like functional capacity," Blood, vol. 106, no. 7, pp. 2347-2355, 2005.

[94] A. K. Tsirogianni, N. M. Moutsopoulos, and H. M. Moutsopoulos, "Wound healing: immunological aspects," Injury, vol. 37, no. 1, supplement 1, pp. S5-S12, 2006.

[95] N. G. Frangogiannis, C. W. Smith, and M. L. Entman, "The inflammatory response in myocardial infarction," Cardiovascular Research, vol. 53, no. 1, pp. 31-47, 2002.

[96] M. De Palma, M. A. Venneri, R. Galli, et al., “Tie2 identifies a hematopoietic lineage of proangiogenic monocytes required for tumor vessel formation and a mesenchymal population of pericyte progenitors," Cancer Cell, vol. 8, no. 3, pp. 211-226, 2005.

[97] K. G. Peters, C. D. Kontos, P. C. Lin, et al., "Functional significance of Tie2 signaling in the adult vasculature," Recent Progress in Hormone Research, vol. 59, pp. 51-71, 2004.

[98] M. A. Venneri, M. De Palma, M. Ponzoni, et al., "Identification of proangiogenic TIE2-expressing monocytes (TEMs) in human peripheral blood and cancer," Blood, vol. 109, no. 12, pp. 5276-5285, 2007.

[99] C. Murdoch, S. Tazzyman, S. Webster, and C. E. Lewis, "Expression of Tie-2 by human monocytes and their responses to angiopoietin-2," The Journal of Immunology, vol. 178, no. 11, pp. 7405-7411, 2007.

[100] M. Anghelina, P. Krishnan, L. Moldovan, and N. I. Moldovan, "Monocytes and macrophages form branched cell columns in matrigel: implications for a role in neovascularization," Stem Cells and Development, vol. 13, no. 6, pp. 665676, 2004.

[101] M. Anghelina, P. Krishnan, L. Moldovan, and N. I. Moldovan, "Monocytes/macrophages cooperate with progenitor cells during neovascularization and tissue repair: conversion of cell columns into fibrovascular bundles," The American Journal of Pathology, vol. 168, no. 2, pp. 529-541, 2006.

[102] N. I. Moldovan, P. J. Goldschmidt-Clermont, J. ParkerThornburg, S. D. Shapiro, and P. E. Kolattukudy, "Contribution of monocytes/macrophages to compensatory neovascularization: the drilling of metalloelastase-positive tunnels in ischemic myocardium," Circulation Research, vol. 87, no. 5, pp. 378-384, 2000.

[103] K. Urbanek, M. Rota, S. Cascapera, et al., "Cardiac stem cells possess growth factor-receptor systems that after activation regenerate the infarcted myocardium, improving ventricular function and long-term survival," Circulation Research, vol. 97, no. 7, pp. 663-673, 2005.

[104] M. A. Laflamme, S. Zbinden, S. E. Epstein, and C. E. Murry, "Cell-based therapy for myocardial ischemia and infarction: pathophysiological mechanisms," Annual Review of Pathology, vol. 2, pp. 307-339, 2007.

[105] C. Badorff, R. P. Brandes, R. Popp, et al., "Transdifferentiation of blood-derived human adult endothelial progenitor cells into functionally active cardiomyocytes," Circulation, vol. 107, no. 7, pp. 1024-1032, 2003.
[106] A. Deten, H. C. Volz, S. Clamors, et al., "Hematopoietic stem cells do not repair the infarcted mouse heart," Cardiovascular Research, vol. 65, no. 1, pp. 52-63, 2005.

[107] M. Alvarez-Dolado, R. Pardal, J. M. Garcia-Verdugo, et al., "Fusion of bone-marrow-derived cells with Purkinje neurons, cardiomyocytes and hepatocytes," Nature, vol. 425, no. 6961, pp. 968-973, 2003.

[108] J. Endo, M. Sano, J. Fujita, et al., "Bone marrow-derived cells are involved in the pathogenesis of cardiac hypertrophy in response to pressure overload," Circulation, vol. 116, no. 10, pp. 1176-1184, 2007.

[109] J. M. Nygren, S. Jovinge, M. Breitbach, et al., "Bone marrowderived hematopoietic cells generate cardiomyocytes at a low frequency through cell fusion, but not transdifferentiation," Nature Medicine, vol. 10, no. 5, pp. 494-501, 2004.

[110] W. Dai, S. L. Hale, and R. A. Kloner, "Role of a paracrine action of mesenchymal stem cells in the improvement of left ventricular function after coronary artery occlusion in rats," Regenerative Medicine, vol. 2, no. 1, pp. 63-68, 2007.

[111] S. Ohnishi, H. Sumiyoshi, S. Kitamura, and N. Nagaya, "Mesenchymal stem cells attenuate cardiac fibroblast proliferation and collagen synthesis through paracrine actions," FEBS Letters, vol. 581, no. 21, pp. 3961-3966, 2007.

[112] M. Takahashi, T.-S. Li, R. Suzuki, et al., "Cytokines produced by bone marrow cells can contribute to functional improvement of the infarcted heart by protecting cardiomyocytes from ischemic injury," American Journal of Physiology, vol. 291, no. 2, pp. H886-H893, 2006.

[113] L. Timmers, S. K. Lim, F. Arslan, et al., "Reduction of myocardial infarct size by human mesenchymal stem cell conditioned medium," Stem Cell Research, vol. 1, no. 2, pp. 129-137, 2007.

[114] T. Kinnaird, E. Stabile, M. S. Burnett, et al., "Local delivery of marrow-derived stromal cells augments collateral perfusion through paracrine mechanisms," Circulation, vol. 109, no. 12, pp. 1543-1549, 2004.

[115] M. Heil and W. Schaper, "Influence of mechanical, cellular, and molecular factors on collateral artery growth (Arteriogenesis)," Circulation Research, vol. 95, no. 5, pp. 449-458, 2004.

[116] B. J. Capoccia, R. M. Shepherd, and D. C. Link, "G-CSF and AMD3100 mobilize monocytes into the blood that stimulate angiogenesis in vivo through a paracrine mechanism," Blood, vol. 108, no. 7, pp. 2438-2445, 2006.

[117] A. Kawamoto, T. Tkebuchava, J.-I. Yamaguchi, et al., "Intramyocardial transplantation of autologous endothelial progenitor cells for therapeutic neovascularization of myocardial ischemia," Circulation, vol. 107, no. 3, pp. 461468, 2003.

[118] R. M. Shepherd, B. J. Capoccia, S. M. Devine, et al., "Angiogenic cells can be rapidly mobilized and efficiently harvested from the blood following treatment with AMD3100," Blood, vol. 108, no. 12, pp. 3662-3667, 2006.

[119] T. Kobayashi, K. Hamano, T.-S. Li, et al., "Enhancement of angiogenesis by the implantation of self bone marrow cells in a rat ischemic heart model," Journal of Surgical Research, vol. 89, no. 2, pp. 189-195, 2000.

[120] G. V. Silva, S. Litovsky, J. A. R. Assad, et al., "Mesenchymal stem cells differentiate into an endothelial phenotype, enhance vascular density, and improve heart function in a canine chronic ischemia model," Circulation, vol. 111, no. 2, pp. 150-156, 2005. 
[121] T. Ziegelhoeffer, B. Fernandez, S. Kostin, et al., "Bone marrow-derived cells do not incorporate into the adult growing vasculature," Circulation Research, vol. 94, no. 2, pp. 230-238, 2004.

[122] L. Wang, W. Ma, R. Markovich, J.-W. Chen, and P. H. Wang, "Regulation of cardiomyocyte apoptotic signaling by insulinlike growth factor I," Circulation Research, vol. 83, no. 5, pp. 516-522, 1998.

[123] K. Kitta, R. M. Day, T. Ikeda, and Y. J. Suzuki, "Hepatocyte growth factor protects cardiac myocytes against oxidative stress-induced apoptosis," Free Radical Biology and Medicine, vol. 31, no. 7, pp. 902-910, 2001.

[124] E. Iwai-Kanai, K. Hasegawa, M. Fujita, et al., "Basic fibroblast growth factor protects cardiac myocytes from iNOSmediated apoptosis," Journal of Cellular Physiology, vol. 190, no. 1, pp. 54-62, 2002. 

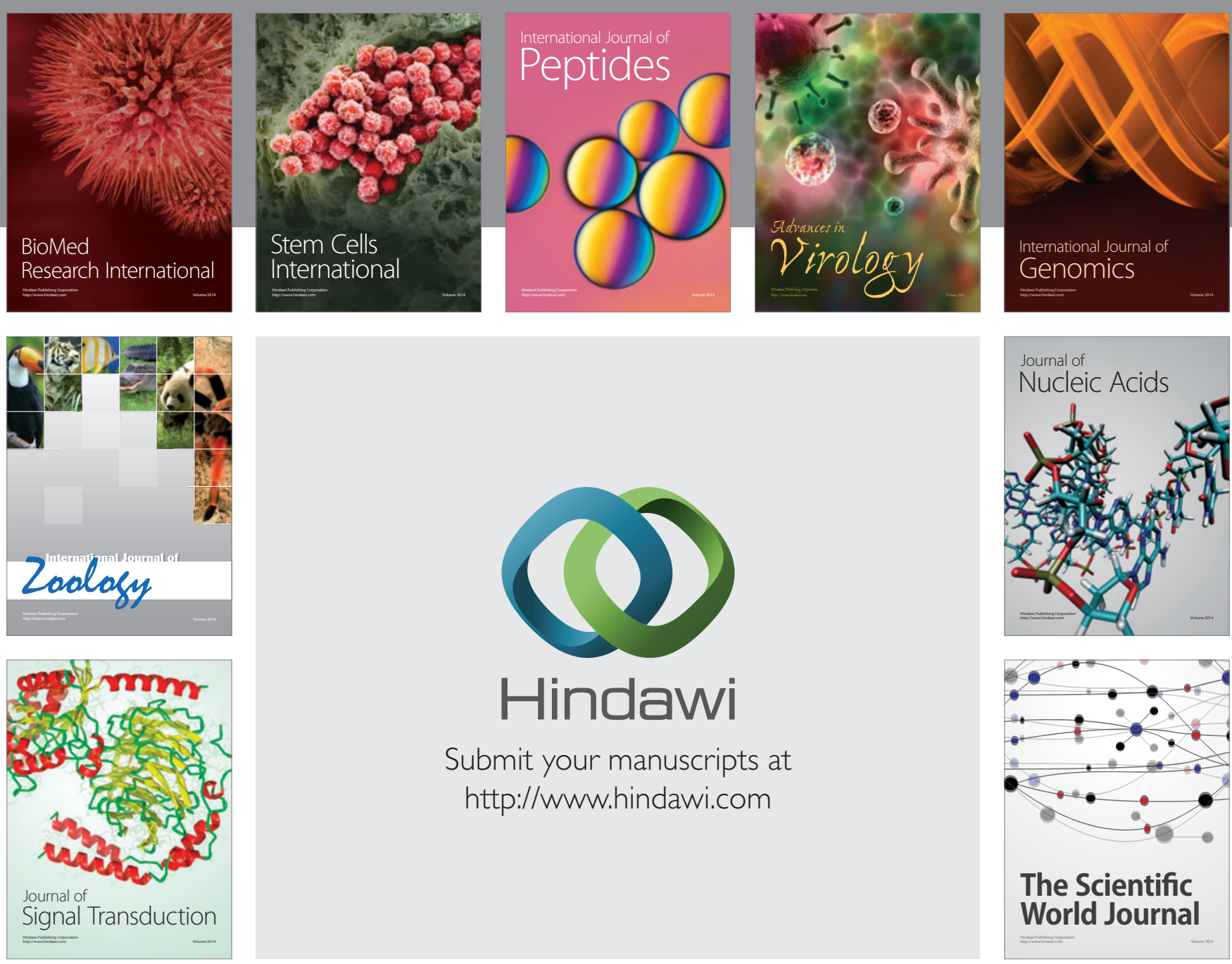

Submit your manuscripts at

http://www.hindawi.com
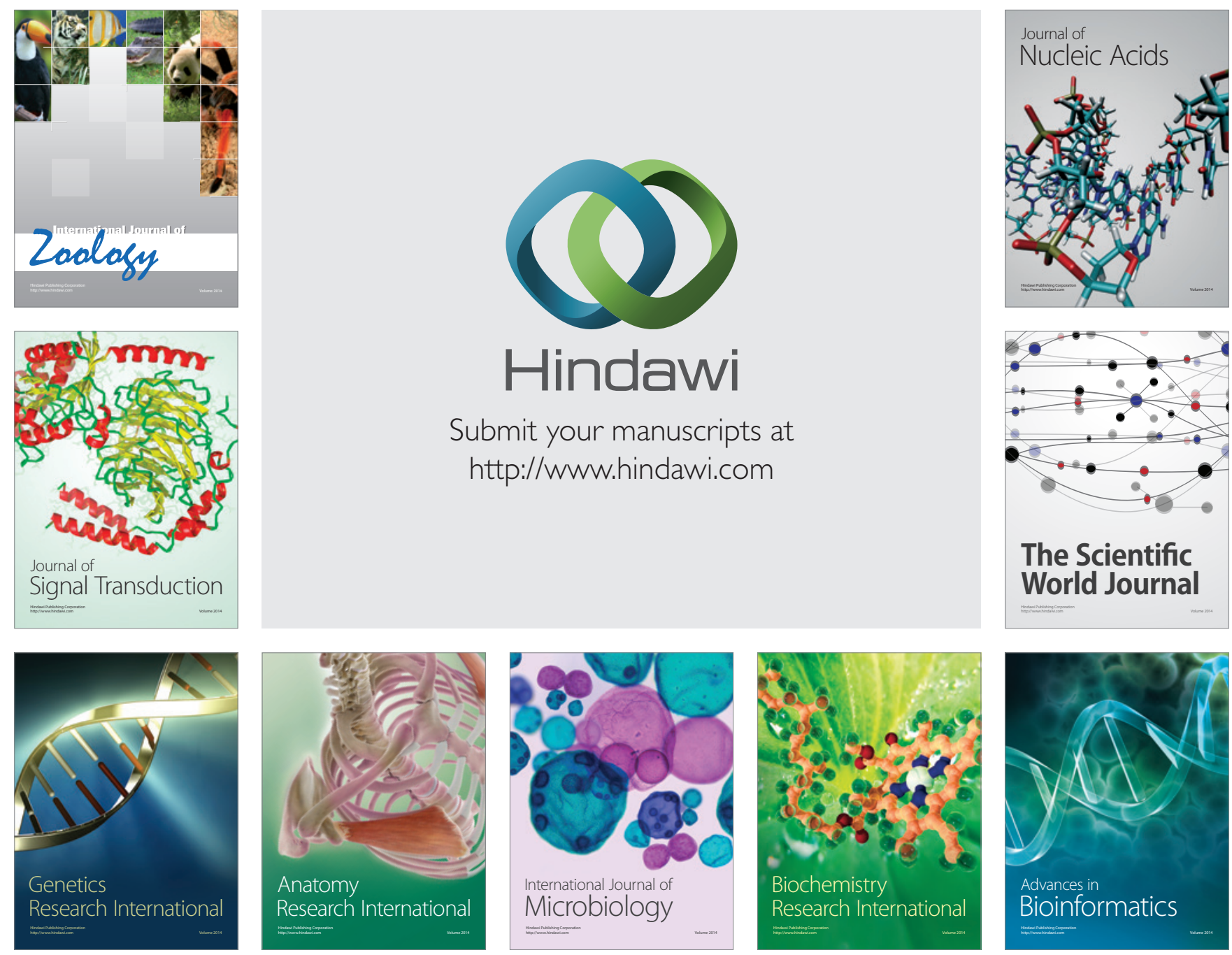

The Scientific World Journal
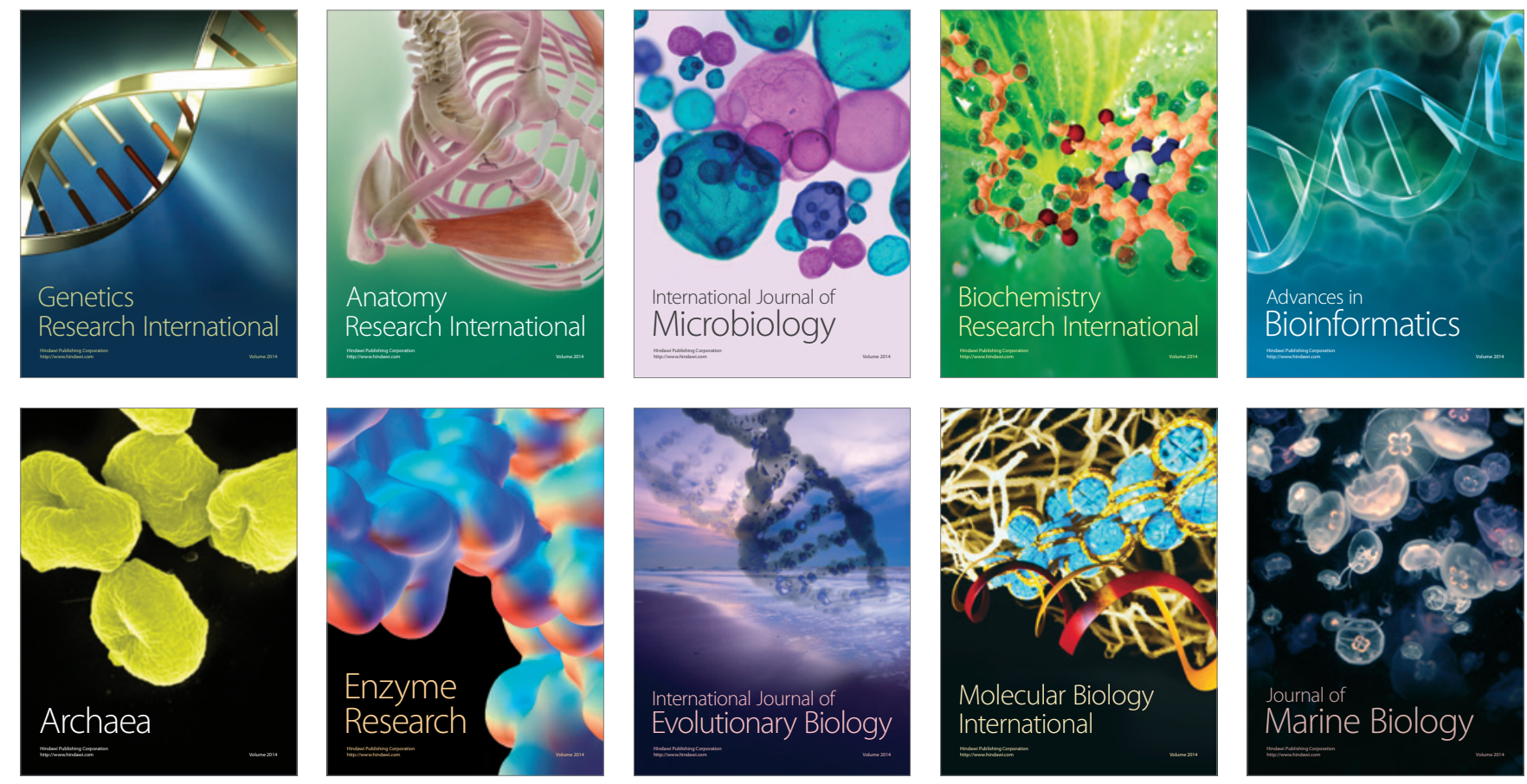